\title{
A Cost Estimating Framework for Electronic, Electrical and Electromechanical (EEE) Components Obsolescence within the Use-Oriented Product-Service Systems Contracts
}

\author{
Francisco J. Romero Rojo ${ }^{1}$, Rajkumar Roy ${ }^{1}$, Essam Shehab ${ }^{1}$, Kalyan Cheruvu ${ }^{1}$ and \\ Phil Mason ${ }^{2}$ \\ ${ }^{1}$ Decision Engineering Centre, Manufacturing Department, Cranfield University, Cranfield, \\ Bedfordshire, MK43 0AL, UK. \{f.romerorojo;r.roy;e.shehab\}@cranfield.ac.uk \\ ${ }^{2}$ GE Aviation Systems, Bishops Cleeve, Cheltenham, Gloucestershire, GL52 8SF, UK. \\ phil.mason3@ge.com
}

\section{Abstract}

This paper provides a cost estimating framework for the Electrical, Electronic and Electromechanical (EEE) components obsolescence, which represents the main source of obsolescence issues due to the increasingly short life cycle of these types of components. The framework comprises a number of areas, namely "Component Complexity Levels", "Obsolescence Management Levels", "Obsolescence Resolution Profiles" and "Obsolescence Cost Metrics". Several studies, based on literature and interaction with numerous obsolescence management experts from industry, have been employed in this research, following a systematic approach. The framework is able to estimate the non-recurring cost of obsolescence during the contracted period within the in-service phase. This is based on the information available at the bidding stage concerning the Product Breakdown Structure (PBS) and the obsolescence management strategy deployed. This framework has been validated at four different UK organisations in the defence and aerospace sectors using seven case studies, one of which is presented in this paper in detail.

\section{Keywords}

Obsolescence; Cost estimating model; EEE; Obsolescence Management; DMSMS 


\section{INTRODUCTION}

The aim of this paper is to present a framework that can be used at the bidding stage of support contracts to estimate the obsolescence non-recurring engineering (NRE) costs incurred during the contracted period. This framework is the result of a comprehensive literature review and interaction with industry using interviews, group meetings and workshops. The basis of this framework relies on the results of the "obsolescence resolution profiles" study [1] and the "obsolescence cost metrics" study [2]. The framework has also been validated by numerous obsolescence experts following an iterative process using nine case studies from industry.

The remaining sections of this paper are organized as follows: Section 2 shows the current trends in obsolescence management within Product-Service System (PSS) business models. Section 3 presents the related research on the areas of obsolescence and cost estimating. Section 4 describes the research methodology. The development of the EEE obsolescence cost estimating framework is presented in Section 5. The rationale that this framework follows is explained in Section 6 and the application to a case study is presented in detail, together with the results of seven case studies, in Section 7. Finally, the discussion about the strengths and weaknesses of the framework is provided in Section 8 , and the concluding remarks and further work in this topic are explained in Section 9.

\section{OBSOLESCENCE MANAGEMENT WITHIN PRODUCT-SERVICE SYSTEMS}

In sectors such as defence and aerospace, the life-cycle of a sustainment-dominated system can be extended over many decades. These systems are usually composed of low volume complex electronics, which are affected by the fast changing market trends and the ongoing technical revolution in the electronics industry [3]. Due to the high costs and long life times associated with technology insertion and design refresh, these systems often fall behind the technology wave $[4,5]$. This explains why many components are reaching the end-of-life at increased rates in many avionics and military systems $[6,7]$. Therefore, one of the main problems that these systems unquestionably face during their lifetime is obsolescence [8,9]. A component becomes obsolete when it is no longer available from stock of its own spares, 
procurable or produced by its manufacturer or suppliers [10,11]. The impact that obsolescence has on the life-cycle cost of sustainment-dominated systems should not be neglected. For instance, the obsolescence issues cost up to $\$ 750$ million annually according to the US Navy estimations [12]. In fact, according to the UK Ministry of Defence (MoD) Obsolescence Manager for the Eurofighter Typhoon project, "obsolescence is number 2 risk to the project".

Currently, the defence environment is moving towards new types of agreement such as capability and availability based contracts, which are enabled by Product-Service System (PSS) business models [13]. PSS can be defined as "an integrated product and service offering that delivers value in use" [14]. It can be classified into three main categories: $[15,16]$

1. Product-oriented, where the tangible product is owned by the consumer and additional services, such as maintenance, are provided. This business model is usually referred to as traditional spares and repairs contract.

2. Use-oriented, where the ownership of the tangible product can be retained by the service provider or transferred to the customer, but the service provider is responsible for ensuring that the product is available. This business model is usually referred to as an availability contract.

3. Result-oriented, where the customer and service provider agree on a desired outcome without necessarily specifying the product involved. This business model is usually referred to as a capability contract.

The increased level of service provides the customer with higher value at reduced through-life cost. This transition is shifting the responsibilities for managing and solving obsolescence issues from the customer to the prime contractor and industry work share partners. Therefore, this new scenario has triggered the need to estimate the cost of obsolescence at the bidding stage, so it can be included in the support contract. Therefore, the framework presented in this paper enables the transition from traditional to availability contracts, including obsolescence in the contractual terms. 


\section{RELATED RESEARCH}

Most of the research carried out so far on obsolescence has focused primarily on how to manage, mitigate and resolve it $[17,18]$. For instance, some studies have been carried out on uprating electronic components, testing them beyond their designed operational characteristics (e.g. temperature), in order to replace obsolete components with an alternative $[19,20]$. Significant emphasis has been placed on the need to manage obsolescence proactively and to prepare an obsolescence management plan (OMP) to reduce the impact of obsolescence issues [21]. Many authors have indicated that collaboration among different projects and organisations, by sharing data about common obsolescence problems, is the next step required to reduce the obsolescence costs further $[18,22]$. Additionally, some research has been carried out to consider obsolescence at the design stage, as it can reduce the obsolescence risk during the lifecycle of the system [23,24]. An example of this could be future proofing of designs based on the supplier's technology roadmap and incorporation of changes within the board design to accommodate new parts that are subject to change (i.e. die shrinkage). Currently, this practice is not very widespread but it is increasing, especially in sectors with high level of technology such as defence and aerospace, where suppliers are encouraged to share this information under partnering agreements with the system's integrator (prime contractor). Some authors have done research on the effects that component standardisation may have on the life-cycle cost of systems, concluding that it will mitigate the impact of obsolescence and hence reduce its cost [25]. There is also research on the interchangeability of components, which supports the selection of replacements for the obsolete component $[21,26]$.

From 1994, the use of commercial off-the-shelf (COTS) in the defence sector has escalated as a result of the "Perry's directive" from the US Department of Defence (DoD) [27]. However, there is no consensus about the suitability of this measure to tackle obsolescence problems. Several authors $[18,28,29]$ support the use of COTS to mitigate obsolescence while others are more sceptical about this, and consider it as a double-edged sword, because COTS usually have a short lifecycle and their performance is limited in many environments $[12,30]$. 
Special effort has been put into developing models and techniques to forecast obsolescence of electronic components. The "availability factor" method and the "scorecard" approach have been traditionally used for this purpose, but their accuracy is questionable $[10,17]$. Therefore, Solomon et al. [10] developed a lifecycle forecasting methodology for electronic components, that takes into account both market and technology factors. Likewise, Josias et al. [31] developed a multiple regression model for forecasting obsolescence of microprocessors. More recently, Sandborn et al. [32] developed a data-mining-based approach to electronic part obsolescence forecasting, which can be applied when there are identifiable evolutionary parametric drivers. Additionally, Sandborn et al. [33] have developed a methodology for generating algorithms that can be used to predict the obsolescence dates for electronic parts that do not have clear evolutionary parametric drivers.

Singh, Sandborn and Feldman, from the University of Maryland, designed a software tool that enables the prediction of the optimum design refresh plan (MOCA tool) $[34,35]$. This tool simultaneously optimises multiple redesigns and multiple obsolescence mitigation approaches, based on forecasted electronic part obsolescence [32,36]. Additionally, Feng et al. [37] developed the Life of Type Evaluation (LOTE) tool for optimizing last time buy (LTB) quantities to minimize lifecycle cost.

In terms of obsolescence cost estimation, the MoD and the DoD have carried out cost metric studies for obsolescence resolution during the last decade [38]. However, opportunities for improvement have been pinpointed by many obsolescence experts [17]. Some of the limitations identified have been overcome by a set of cost metrics developed by Romero Rojo et al. [2].

The literature review and discussions with many experts from different organisations in the defence and aerospace sector have revealed that little research has been done in the area of cost estimation for obsolescence. The need for a framework that can be systematically used to estimate the NRE cost of obsolescence during the inservice phase at the bidding stage [2] has been identified. This need is justified by the move from traditional contracting for sustainment-dominated systems towards contracting for availability (CFA) in the defence and aerospace sector. This is bringing the prime contractor and the customer to a new scenario in which they need 
to make accurate, consistent and auditable estimations of the obsolescence cost at the bidding stage in order to include it in the contracts [2].

\section{RESEARCH METHODOLOGY}

A systematic approach has been followed in this study, as shown in Figure 1. The first phase aimed to gain an understanding on obsolescence and cost estimation through a literature review and semi-structured interviews with experts from industry. This allowed the identification of key factors and cost drivers for obsolescence, together with the type of information available at different stages of the life-cycle of the system. A MS Excel-based prototype for the cost estimation of obsolescence was developed and iteratively enhanced, based on qualitative validation carried out in collaboration with experts from different organisations. The resulting framework was then quantitatively validated using case studies from industry.

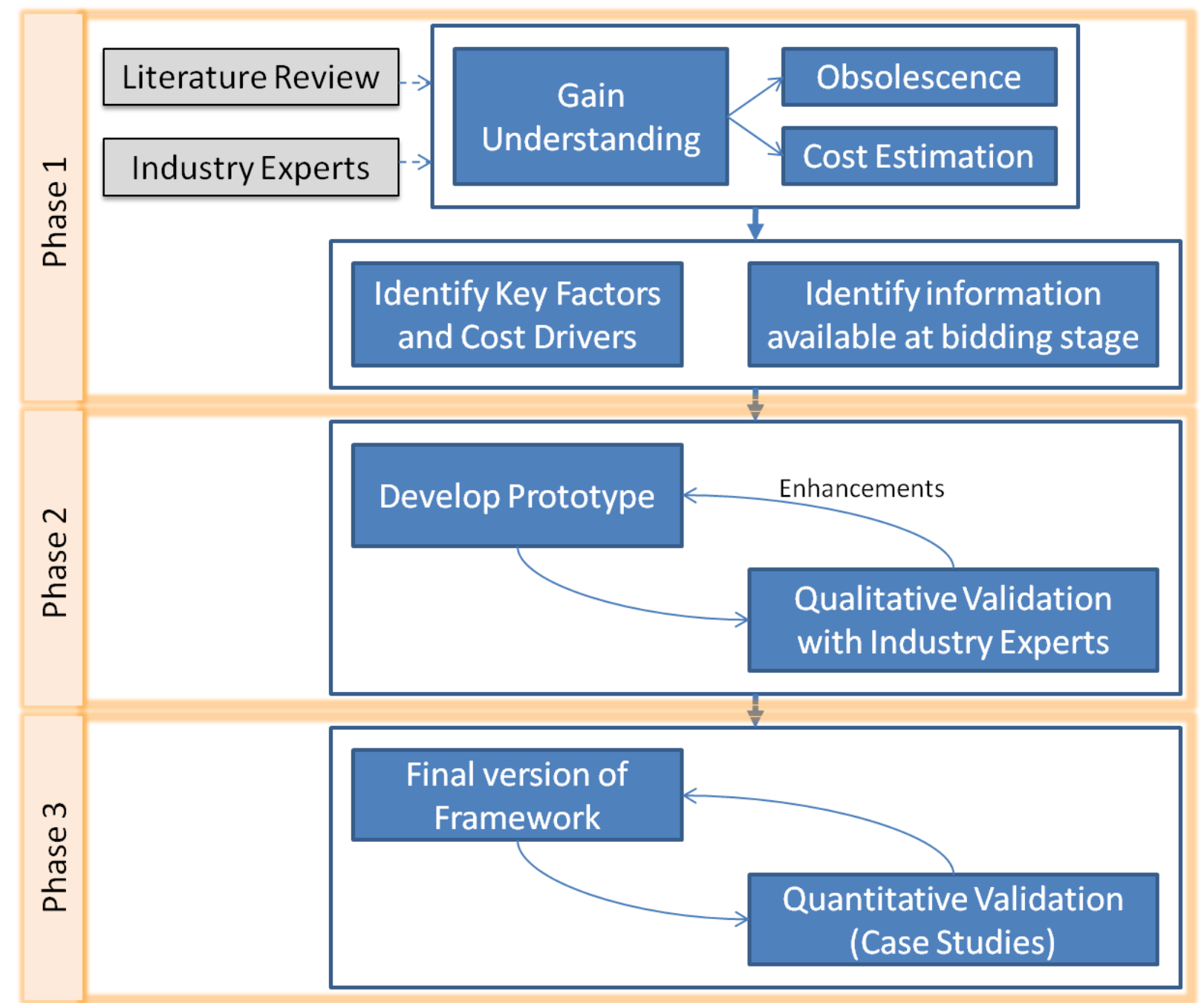

Figure 1 Research Methodology 


\section{EEE-FORCE FRAMEWORK DEVELOPMENT}

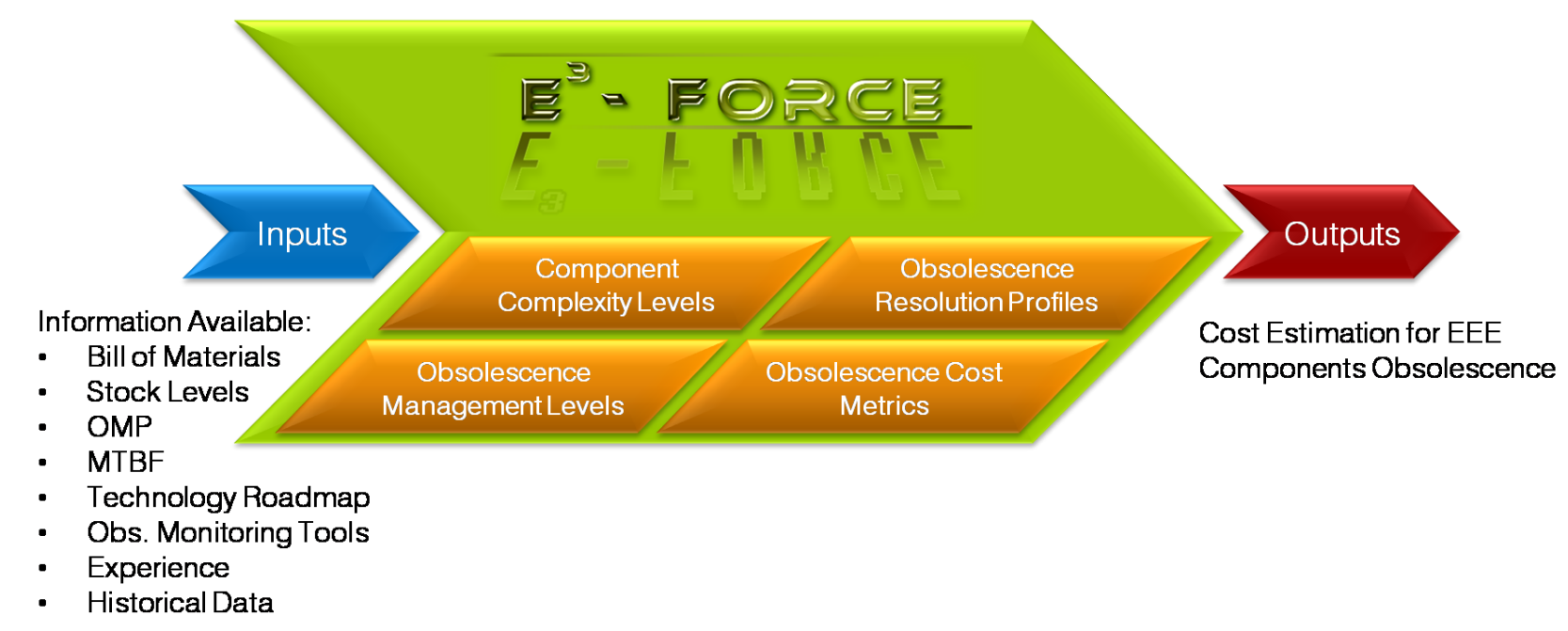

Figure 2 EEE-FORCE Concept

A representation of the Electronic, Electromechanical and Electrical Framework for Obsolescence Robust Cost Estimation (EEE-FORCE) is displayed in Figure 2. It is mainly based on four concepts, namely "Component Complexity Levels", "Obsolescence Management Levels", "Obsolescence Resolution Profiles" and "Obsolescence Cost Metrics", which were developed by means of two studies.

\subsection{TERMINOLOGY: PRODUCT VS. COMPONENT}

The following concepts, "Product" and "Component" are regarded as two consecutive levels to which this framework is applied, regardless of their hierarchical level (e.g. platform, integrated system, system, subsystem, assembly, board, part). "Product" represents the upper of the two levels considered.

o "Component" represents the lowest level of interest to which obsolescence can be managed.

- A "Product" is composed of "Components" and represents the consecutive upper level in the system hierarchy. 


\subsection{OBSOLESCENCE RESOLUTION PROFILES STUDY}

The Obsolescence Resolution Profiles (ORPs) study aims to determine the probability of using each resolution approach to tackle an obsolescence issue for an electronic component. Details of this study are provided in the obsolescence resolution profiles study paper [1]. The main outcomes are:

- A set of definitions for the obsolescence resolution approaches, agreed across the key obsolescence experts in the UK defence sector.

- A classification of the components complexity levels, according to the difficultness of replacing an obsolete component.

- A classification of the obsolescence management levels, according to the level of proactiveness deployed.

- A total of 15 obsolescence resolution profiles, where each one represents the probability of using each obsolescence resolution approach to tackle an obsolescence issue. Each obsolescence resolution profile is characterised by one level of component complexity and one level of obsolescence management proactiveness.

\subsection{OBSOLESCENCE COST METRICS STUDY}

The second study was focused on the development of obsolescence cost metrics (OCM). Details of this study are provided in the obsolescence cost metrics paper [2].

The key cost drivers were reached by consensus:

- Resolution approach applied to solve the obsolescence issue.

- Type of platform.

- Requalification testing required, which depends upon the level of safety/criticality of the obsolete component.

- Level of integration of the obsolete component. This depends upon two factors: 
- The Package Density, which is based on the space available in the product (e.g. Line-replaceable unit (LRU) or assembly) and the level of interaction within the obsolete item.

- The Coupling Level, which is characterised by the number of interfaces that the obsolete item has with adjacent items (e.g. mechanical, optical, electrical, software or communications protocols) and the characteristics of each interface.

\begin{tabular}{|l|c|}
\hline & $\begin{array}{c}\text { NORMALISED } \\
\text { BASE COST (Q) }\end{array}$ \\
\hline Existing Stock & 0.09 \\
\hline LTB & 0.57 \\
\hline Cannibalisation & 0.49 \\
\hline Equivalent & 1.00 \\
\hline Alternative & 1.00 \\
\hline Authorised Aftermarket & 1.29 \\
\hline Emulation & 7.63 \\
\hline Minor Redesign & 6.09 \\
\hline Major Redesign & 28.57 \\
\hline
\end{tabular}

\begin{tabular}{|c|c|}
\hline Type of Platform & FACTOR 3 (C) \\
\hline Space & 1.3 \\
\hline Air / Safety Critical & 1 \\
\hline Sea/Submersible & 0.73 \\
\hline Land-Mobile (military) & 0.53 \\
\hline Land-Fixed (consumer) & 0.3 \\
\hline
\end{tabular}

\begin{tabular}{|c|c|}
\hline $\begin{array}{c}\text { Requalification } \\
\text { Required }\end{array}$ & FACTOR $4(\mathrm{X})$ \\
\hline Yes & 1 \\
\hline No & 0 \\
\hline
\end{tabular}

\begin{tabular}{|l|c|c|c|c|}
\hline \multirow{2}{*}{\multicolumn{1}{|c|}{ FACTOR 1 (A) }} & \multicolumn{4}{c|}{ Level of Integration } \\
\cline { 2 - 5 } & Small & Medium & Large & Very Large \\
\hline Existing Stock & 1 & 1 & 1 & 1 \\
\hline LTB & 1 & 1 & 1 & 1 \\
\hline Cannibalisation & 1 & 1.47 & 2 & 2.65 \\
\hline Equivalent & 1 & 1 & 1 & 1 \\
\hline Alternative & 1 & 1 & 1 & 1 \\
\hline Authorised Aftermarket & 1 & 1 & 1 & 1 \\
\hline Emulation & 1 & 5.62 & 13.11 & 71.16 \\
\hline Minor Redesign & 1 & 2.77 & 3.96 & 14 \\
\hline Major Redesign & 1 & 2 & 4 & 50 \\
\hline
\end{tabular}

\begin{tabular}{|l|c|c|c|c|}
\hline \multirow{2}{*}{ FACTOR 2 (B) } & \multicolumn{4}{c|}{ Level of Integration } \\
\cline { 2 - 5 } & Small & Medium & Large & Very Large \\
\hline Existing Stock & 0 & 0 & 0 & 0 \\
\hline LTB & 0 & 0 & 0 & 0 \\
\hline Cannibalisation & 0 & 0 & 0 & 0 \\
\hline Equivalent & 0 & 0 & 0 & 0 \\
\hline Alternative & 1.86 & 1.86 & 3.34 & 5.14 \\
\hline Authorised Aftermarket & 1.89 & 1.89 & 3.4 & 4.73 \\
\hline Emulation & 0.95 & 1.62 & 5.19 & 29.62 \\
\hline Minor Redesign & 1.35 & 5.09 & 7.48 & 11.78 \\
\hline Major Redesign & 1.5 & 18 & 30 & 87.45 \\
\hline
\end{tabular}

Figure 3 Obsolescence Cost Metrics (non-dimensional) [2] 
The cost metrics illustrated in Figure 3 represent the non-recurring costs of resolving an obsolescence issue using each of the resolution approaches. These non-recurring obsolescence costs are calculated, according to the parameters that characterise the obsolescence issue, by applying the following formula, combining the base cost with the four factors.

$$
\begin{gathered}
\text { Cost }=\text { BaseCost } \times(\text { Factor } 1+\text { Factor } 2 \times \text { Factor } 3 \times \text { Factor } 4) \\
\text { Cost }=Q \times(A+B \times C \times X)
\end{gathered}
$$

- Factor $1(A)$ is applied to estimate the resolution cost without requalification. It depends upon the resolution approach and the level of integration.

- Factor2 $(B)$ is applied to estimate the requalification cost. It depends upon the resolution approach and the level of integration.

- Factor3 (C) is applied to take into account the type of platform in the estimation of the re-qualification cost.

- Factor $4(\mathrm{X})$ indicates whether requalification testing is required or not.

The resulting cost metrics have been normalised, making the base cost nondimensional as shown in Figure 3. This normalisation makes these metrics timeless, allowing them to be used for any project regardless of the inflation and fluctuations in the currency exchange. However, it is necessary to generate the cost metrics that will be applied to a particular project by benchmarking one value based on past experience. For instance, if it is known for a particular project that the NRE cost of solving an obsolescence issue - with no requalification required and small level of integration - by finding an equivalent is $£ 3,500$, then the base cost for minor redesign is $£ 3,500 \times 6.09=£ 21,300$, and the rest of cost metrics can be analogously calculated. 


\section{EEE-FORCE COST ESTIMATION PROCESS}

Figure 4 outlines how the information input to the framework is combined to estimate the NRE cost. The three main elements are:

- Number of obsolescence issues during the contracted period

- Obsolescence Resolution Profiles (ORP)

- Obsolescence Cost Metrics (OCM)

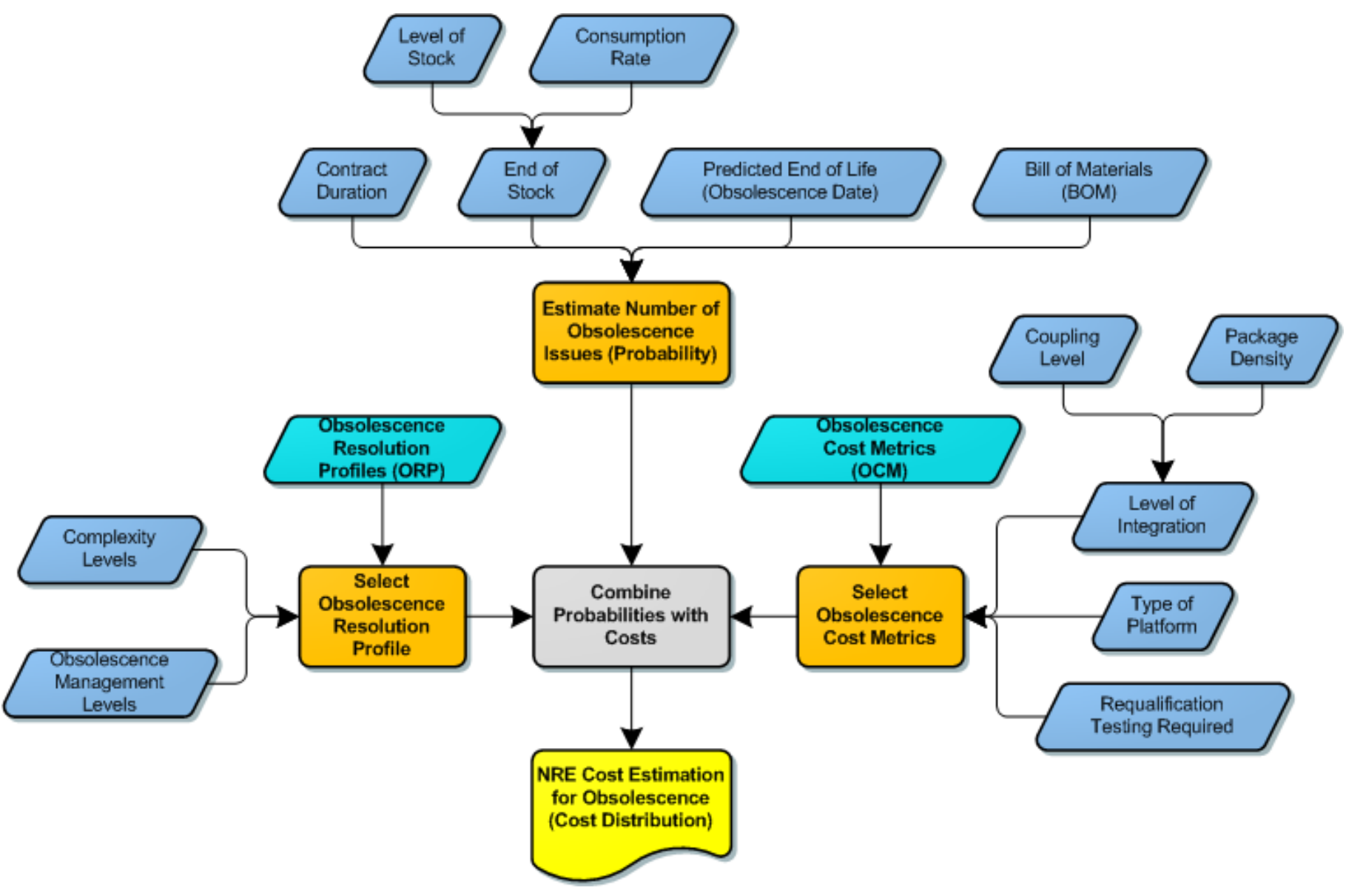

Figure 4 EEE Obsolescence Cost Estimating Framework Structure

The number of obsolescence issues and its probability is calculated based on the information available, which may include:

- Bill of Materials

- Contract duration

- Level of stock exclusive to the project of concern

- Consumption rate 
- Predicted end of life (obsolescence date)

- Mean Time Between Failures (MTBF)

- Fleet size

- Number of same components per platform

- Percentage of scrap - It represents the percentage of items that are discarded once they fail. The rest are repaired and go back to stock.

- Probability of running out of stock during the contracted period

The consumption rate (items used per year) for each component can be input directly by the user or it can be calculated using the following formula:

Consumption Rate $=\frac{\text { Fleet size } \times \text { No of same comp.per platform } \times \% \text { of Scrap }}{M T B F}$

The framework combines this information with the level of stock available (exclusive to the project of concern) to estimate the date by which the stock will run out if no more is bought using the following formula:

Date Run out of Stock $=$ Date Review $+\frac{365 \times \text { Stock }}{\text { Consumption Rate }}$

If that data is not available or the stock is not exclusive to the project of concern, the user will indicate the probability of running out of stock during the contracted period based on expert judgement using the following scale:

- $100 \%$ - It is certain that will run out of stock during the contracted period

- $75 \%$ - High probability of running out of stock during the contracted period

- $50 \%$ - Medium probability of running out of stock during the contracted period

- $25 \%$ - Low probability of running out of stock during the contracted period

- $0 \%$ - It will certainly not run out of stock during the contracted period

The predicted end of life (obsolescence date) may come from an obsolescence monitoring tool or the usage of obsolescence forecasting algorithms. If they are not available, or the information related to a particular component is not included in those databases, the user can assess the probability of going obsolete during the contracted period based on expert judgement, using a scale analogous to the one described above. 
An obsolescence issue occurs when a component goes obsolete and runs out of stock during the contracted period. Therefore, when the user relies on expert judgement, the probability of having an obsolescence issue can be calculated using the following formula:

Probability of Obs. Issue = Probability of Becoming Obsolete during the Contracted Period $\times$ Probability of Running Out of Stock during the Contracted Period

For instance, if there is high probability of running out of stock during the contracted period $(75 \%)$ and low probability of going obsolete during the contracted period (25\%), then the Probability of Obs. Issue is equal to $75 \% \times 25 \%=18.75 \%$.

If there is data available that allows estimation of the obsolescence date and the outof-stock date, the probability can be derived from comparing those dates with the end of the contract.

The five steps followed to estimate the NRE cost are outlined in Figure 5. In Step 1 it requires the user information in terms of who is providing the information and when, in order to provide traceability for the cost estimate. Step 2 requires information about the system, including the type of platform, support contract duration, breakdown of the system into product and level of information available for each product. The framework is flexible enough to adapt to any level of information available and still provide a cost estimate, where the level of uncertainty is related to the level of information available and its reliability. For those products for which detailed information is available, it will be provided in Step 3A; whereas Step 3B will be used when little information is available for a product, and hence, expert judgement is required [39]. In Step 4 and Step 5 it is possible to customise and calibrate the Obsolescence Resolution Profiles and the Obsolescence Cost Metrics respectively. 


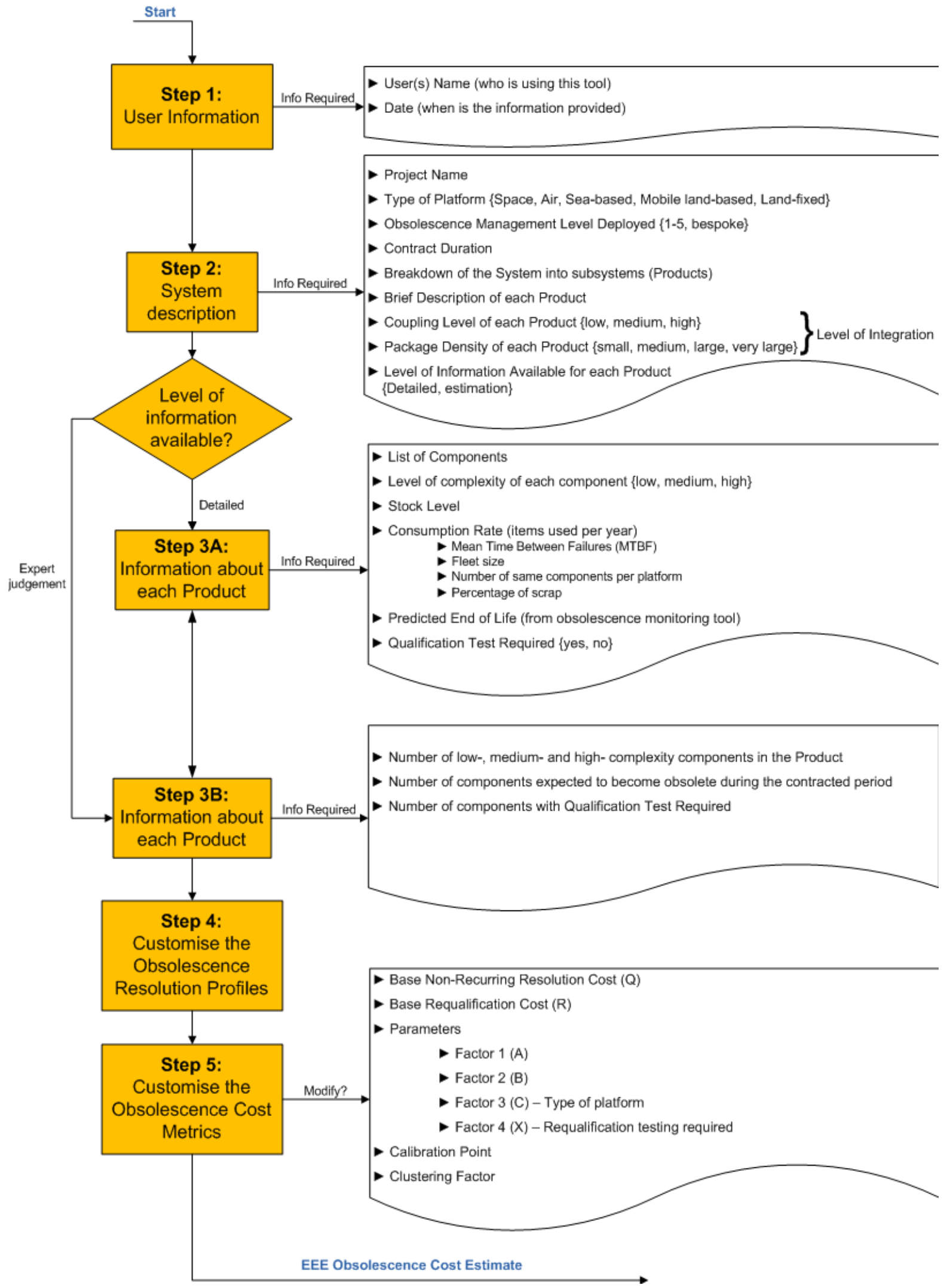

Figure 5 EEE-FORCE Cost Estimating Process 
The Obsolescence Resolution Profiles resulting from the ORP study can be customised to reflect better the current practice in the project for which the framework is going to be applied. Similarly, the Obsolescence Cost Metrics can be customised as well if historical data is available.

The estimated number of obsolescence issues during the contracted period is produced by the framework undertaking a risk assessment based on the contract duration, level of stock, consumption rate and predicted end of life for all the components included in the bill of materials (Figure 4). This risk assessment analyses the probability for each component of simultaneously running out of stock and reaching the end of life before the contract ends.

The fact that emulation, minor and major redesigns may resolve several obsolescence issues simultaneously and avoid forthcoming ones has generally been ignored in traditional cost accounting done by obsolescence management groups. Therefore it was necessary to introduce the concept of the "clustering factor" to address this issue. The clustering factor represents the number of redesigns that would be applied to solve 100 obsolescence issues requiring a redesign. For instance, if the clustering factor is $30 \%$, it represents that if there are ten obsolescence issues requiring a minor redesign, only three minor redesigns will be required rather than ten.

The level of uncertainty involved in the following inputs is taken into account in this framework:

- Consumption rate - a plus/minus percentage is defined around the figure provided, and a normal distribution is assumed.

- Obsolescence date - a plus/minus number of months is defined around the figure provided.

- Number of components, number of obsolete components and number of requalification testing - When detailed information is not available, the estimates will be provided together with a plus/minus percentage, and a normal distribution is assumed. This percentage will be based on the level of confidence on the figure provide.

- Cost metrics - For the base cost $(Q)$ (see Figure 3), a normal distribution is considered, where the mean is the figure provided as "base cost" and the 
standard deviation has been extrapolated from the results of the MoD cost metrics study [38].

- Clustering factor - a plus/minus percentage is defined around the figure provided, and a normal distribution is assumed.

\section{VALIDATION CASE STUDY}

The EEE-FORCE framework has been validated by applying it to seven case studies across four different companies in the UK defence sector. For the analysis of the case studies, the output provided by the EEE-FORCE framework was compared with the cost estimated at the engineering level, which provides the basis for the price agreed with the customer when signing the contract, after including the profit margins and inflation considerations. A representative case study is provided in detail for this paper. It covers the obsolescence management for the support of part of the avionics in a military aircraft within the in-service phase of the CADMID ${ }^{1}$ cycle, contracted for ten years. The terms of the contract include covering proactive notification of obsolescence issues, last time buy (LTB) and FFF replacements. This case study has been chosen due to the availability of this information and because it represents a good example of the application of the proposed framework.

This case study was carried out in collaboration with the Obsolescence \& Reliability Manager of the prime contractor, who has 4 years of experience on managing obsolescence. The inputs are summarised in Table 1.

\footnotetext{
${ }^{1}$ The Concept, Assessment, Demonstration, Manufacture, In-service, Disposal (CADMID) cycle was developed as part of SMART Acquisition within the Defence Procurement Agency at the United Kingdom Ministry of Defence (MOD).
} 


\begin{tabular}{|c|c|}
\hline Number of Products & 1 \\
\hline Contract Duration & 10 years \\
\hline Obsolescence Management Level & Bespoke \\
\hline Type of Platform & Air systems / Safety Critical \\
\hline Coupling Level & Medium \\
\hline Package Density & Medium \\
\hline Level of Integration & Medium \\
\hline Number of Components & 270 \\
\hline Level of Information Available & $\begin{array}{ll}\text { - } & \text { List of Components } \\
\text { - Obsolescence Monitoring Tools } \\
\text { - Probability of Running out of Stock } \\
\text { - Obsolescence date (51 components) } \\
\text { - Probability of having an obsolescence } \\
\text { - } \text { issue (219 components) } \\
\text { - Levels of Complexity }\end{array}$ \\
\hline Stock shared for all components? & Yes \\
\hline Requalification Testing Required & None \\
\hline Components Ignored & 0 \\
\hline Obsolescence Resolution Profiles & $\begin{array}{l}\text { Bespoke (based on experience and historical } \\
\text { data) }\end{array}$ \\
\hline Cost Metrics & Bespoke/Default \\
\hline Clustering Factor & $30 \%$ \\
\hline
\end{tabular}

The Obsolescence Resolution Profiles were customised to represent the current practice in this project. As shown in Figure 6, for low-complexity components, there is similar probability of applying equivalent $(52 \%)$ or LTB $(48 \%)$ to solve an obsolescence issue. For a medium-complexity component, it is more likely to find an equivalent $(60 \%)$ than existing stock (20\%) or making a LTB (20\%). An obsolescence issue in a high-complexity component will always be solved by making a LTB (100\%). For this purpose it is important to apply proactive obsolescence management strategies, so the prime contractor can monitor the status of high-complexity components and avoid missing LTB notifications. 


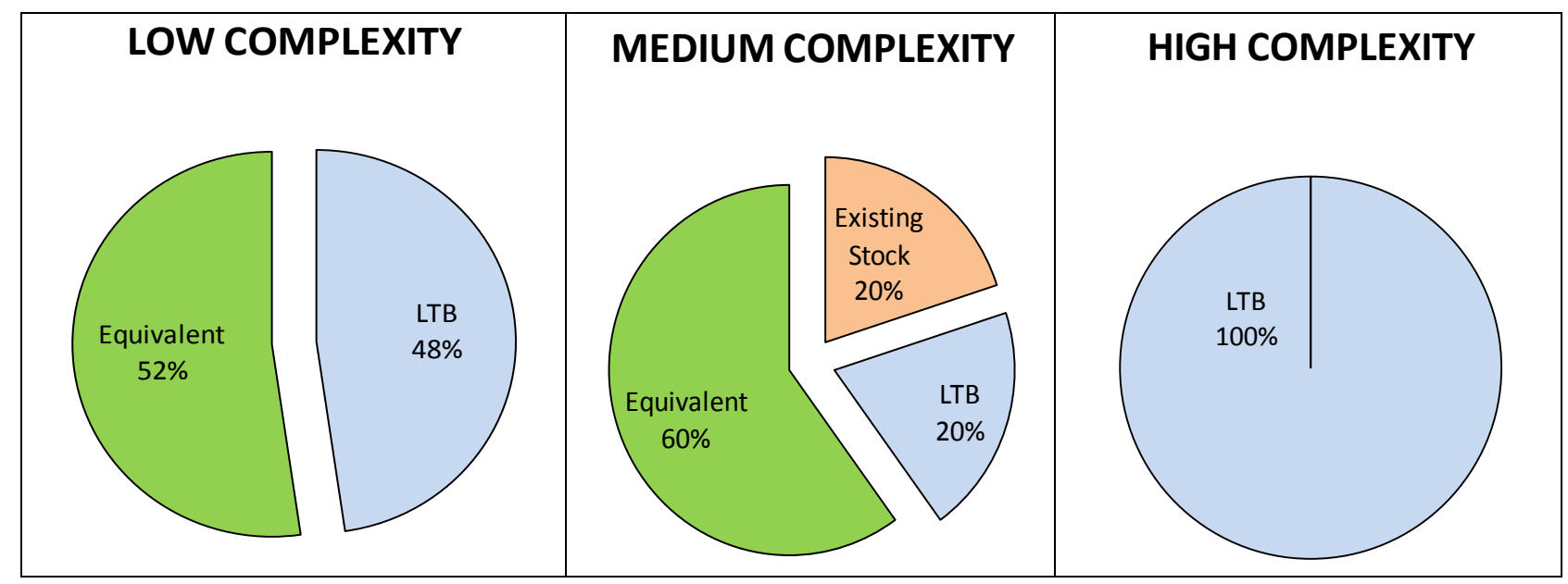

Figure 6 Bespoke Obsolescence Resolution Profiles

As a result, the EEE-FORCE framework predicted a total of 62.5 obsolescence issues during the contract period, and estimated that the NRE cost of solving those obsolescence issues will be $£ 262,985$. The result of running the Monte Carlo Simulation is displayed in Figure 7. It shows that after running 1000 trials, a beta distribution represents the probability of the costs estimated. The mean $(\mu)$ of this distribution is $£ 263,456$ and the standard deviation $(\sigma)$ is $£ 13,897$.

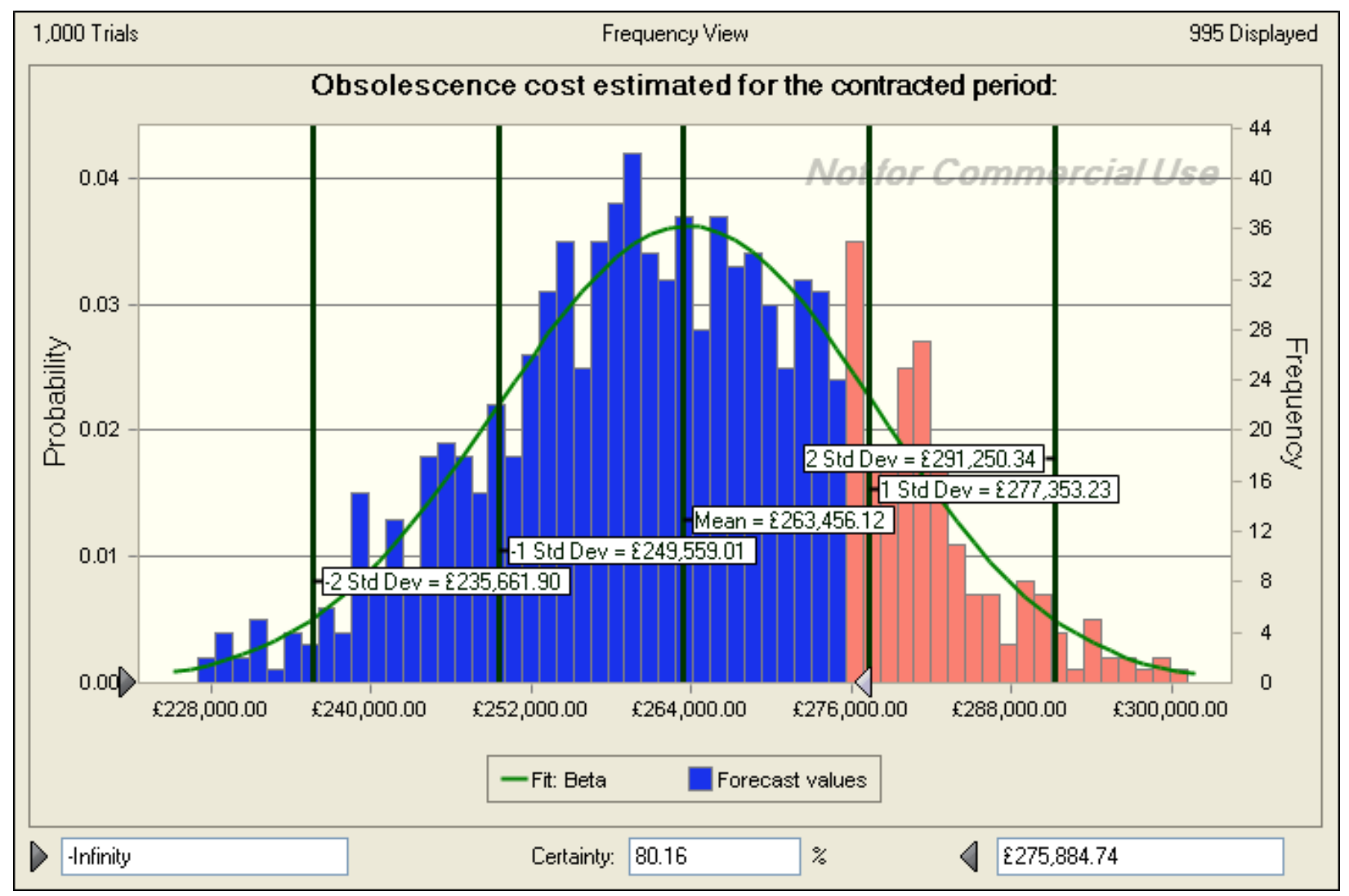

Figure 7 Output of EEE-FORCE after Running Monte Carlo Simulation 
The results were compared with the figures agreed for obsolescence in this contract at the engineering level (not taking into account the inflation), which were calculated using an in-house bespoke model validated with the customer. The obsolescence cost agreed is $£ 259 \mathrm{k}$, which differs in $1.54 \%$ with the EEE-FORCE estimate.

Table 2 Summary of Quantitative Results from Case Study

\begin{tabular}{|c|c|c|c|c|c|c|}
\hline \multirow[b]{2}{*}{ System } & \multirow[b]{2}{*}{$\begin{array}{l}\text { Contract } \\
\text { Duration }\end{array}$} & \multicolumn{3}{|c|}{ EEE-FORCE Estimate } & \multirow{2}{*}{$\begin{array}{l}\text { Contractual } \\
\text { Figure } \\
\text { Agreed at the } \\
\text { Engineering } \\
\text { Level }\end{array}$} & \multirow[b]{2}{*}{$\begin{array}{c}\text { Difference } \\
(\%)\end{array}$} \\
\hline & & $\begin{array}{c}\text { Min. } \\
\text { estimate } \\
\text { (E-2SD) }\end{array}$ & $\begin{array}{c}\text { Most } \\
\text { Likely } \\
\text { estimate } \\
\text { (E) }\end{array}$ & $\begin{array}{c}\text { Max. } \\
\text { estimate } \\
(E+2 S D)\end{array}$ & & \\
\hline Avionics & 10years & $£ 236 k$ & $£ 263 k$ & $£ 277 \mathrm{k}$ & $£ 259 k$ & $+1.54 \%$ \\
\hline Avionics & $\begin{array}{c}\text { Pre- } \\
\text { contract }\end{array}$ & $£ 33 k$ & $£ 43 k$ & $£ 52 k$ & $£ 45 k$ & $-4.44 \%$ \\
\hline $\begin{array}{l}\text { Airborne } \\
\text { Systems }\end{array}$ & 11 years & $£ 5.06 \mathrm{~m}$ & $£ 6.42 \mathrm{~m}$ & $£ 7.79 \mathrm{~m}$ & $£ 6.8 \mathrm{~m}$ & $-5.59 \%$ \\
\hline $\begin{array}{l}\text { Aircraft } \\
\text { systems }\end{array}$ & 5years & $£ 1.62 \mathrm{~m}$ & $£ 1.86 \mathrm{~m}$ & $£ 2.1 \mathrm{~m}$ & $£ 1.7 \mathrm{~m}$ & $+9.41 \%$ \\
\hline Radar & 5years & $£ 2.53 \mathrm{~m}$ & $£ 3.6 \mathrm{~m}$ & $£ 4.67 \mathrm{~m}$ & $£ 3.7 \mathrm{~m}$ & $-2.7 \%$ \\
\hline Avionics & 10years & $£ 2.5 \mathrm{~m}$ & $£ 3.13 \mathrm{~m}$ & $£ 3.76 \mathrm{~m}$ & $\begin{array}{c}(£ 2.4 \mathrm{~m}-£ 3.7 \mathrm{~m}) \\
£ 3.05 \mathrm{~m}\end{array}$ & $+2.62 \%$ \\
\hline Avionics & 10years & $£ 2.55 \mathrm{~m}$ & $£ 3.16 \mathrm{~m}$ & $£ 3.78 \mathrm{~m}$ & $\begin{array}{c}(£ 2.4 \mathrm{~m}-£ 3.7 \mathrm{~m}) \\
£ 3.05 \mathrm{~m}\end{array}$ & $+3.61 \%$ \\
\hline
\end{tabular}

SD - Standard Deviation

The quantitative results of the seven case studies carried out are summarised in Table 2. For all of them, the difference between the estimated cost $(E)$ and the cost agreed in the contract at the engineering level (without inflation considerations) is on average $4.27 \%$, and always lower than $10 \%$. For instance, in the sixth case study shown in the figure, the 3 point estimate provided by the in-house model is $(£ 2.4 \mathrm{~m}$, $£ 3.05 \mathrm{~m}, £ 3.7 \mathrm{~m})$ which is congruent with the EEE-FORCE estimate $(£ 2.5 \mathrm{~m}, £ 3.13 \mathrm{~m}$, $£ 3.76 \mathrm{~m}$ ), where the notation is (minimum, most likely, maximum). The last two case studies are actually referred to the same system, but in the first one all the information has been input in STEP $3 A$ whereas in the second one all the information has been input in STEP 3B for comparative purposes. The results obtained in both 
cases are similar to each other and congruent with the in-house bespoke model. This shows that the EEE-FORCE framework can be applied to different projects and the predictions are at least the same level of accuracy as the in-house bespoke models. These in-house models, which are kept confidentially at these companies, have been developed bespoke for particular projects and validated with past data.

As a result of the verification and validation of the EEE-FORCE framework, a total of eight experts on obsolescence (average of 8.6 years experience on obsolescence) from different organisations across the UK defence sector concur that the key formulae applied in this framework is valid and the outputs are consistent.

\section{DISCUSSIONS}

This research has been mainly focused on EEE components obsolescence in the defence and aerospace sector. However, interviews with obsolescence experts in others fields, such as nuclear and railway, have indicated that there are big similarities for any sustainment-dominated system, whose support is usually contracted following Product-Service System (PSS) business models. Likewise, the EEE-FORCE is regarded as a suitable framework for this type of systems, regardless of the sector in which it is considered.

The concepts and data used for the development of the EEE-FORCE framework are derived from discussions, workshops and interviews with experts in obsolescence rather than from historical data, due to its unavailability. However, the usage of a systematic research methodology, combining the Delphi method and the Critical Incident technique, overcame the problem of basing the research on expert judgement rather than on actual data. It is expected that the appropriate storage of historical data related to obsolescence across different projects may enable in the future the refinement of the figures and concepts generated in this framework.

The Obsolescence Cost Metrics developed in the past by the UK MoD and the US DoD received criticism from many experts in industry. It was highlighted that they can be improved by taking into account other cost factors apart from the resolution approach applied. By means of this study, other key cost drivers were identified and their contribution to costs was assessed. Further research may build on this, refining 
the cost metrics resulting from this study, by analysing actual costs regarding obsolescence issues.

All the experts that participated on the validation of this framework agreed that it is very flexible for two reasons. First, it adapts to any level of information available, which enables the user to apply it at different stages of the CADMID cycle. This provides a key advantage over cost estimating approaches designed for early stages (e.g. parametric) or when detailed information is available (e.g. bottom-up) [40,41], because it provides continuity in the estimates, allows for refinement as more data becomes available. Second, the framework has been designed in a way that the user can easily customise it, by modifying the cost metrics and the ORP.

A set of assumptions have been made in the development of this framework, which may be a possible limitation for its usage. The first one is that this framework is meant to be used for the NRE cost estimation of the obsolescence issues that arise during a support contract, assuming that no technology refresh or capability upgrades take place in this period. Additionally, it is assumed that all the fleet is enhanced during midlife upgrades. Another assumption made is that any component is not expected to become obsolete more than once during the contracted period. In reality, this assumption is only valid when the obsolescence issue is tackled using long-term solution such as LTB or redesigns; whereas the usage of short-term solutions such as alternates or equivalents may result on several obsolescence issues. It is regarded that an obsolescence issue will only contribute to costs for the contract if the level of stock for that item is not enough to cover the contracted period. Emulation, Minor and Major Redesigns may solve several obsolescence issues simultaneously, and the clustering factor is used to represent this fact. A limitation of this framework is the fact that the cost of money is not taken into account. For this purpose, it is not enough to predict the number of obsolescence issues during the contracted period, but also it is necessary to forecast when each obsolescence issue will happen.

The EEE-FORCE framework estimates the cost of obsolescence at the engineering level and this is why the year on year escalation of cost due to inflation is not taken into account. Concepts such as net present value (NPV) and inflation will need to be taken into account for further enhancements of this framework in order to convert the cost estimate into a price for the contract. 


\section{CONCLUDING REMARKS}

The EEE-FORCE framework provides a novel and systematic approach to estimate the NRE cost of solving existing obsolescence issues at the bidding stage and through the life of the contract. This is a publicly available framework based on industry-wide collaboration. It addresses a need triggered by the current move towards contracting for availability, where the obsolescence risk is cascaded down the supply chain. The experts that participated on the validation process concur that this framework is suitable for the cost estimation of obsolescence and some of them have started to apply it to current projects. The intention of the MoD is that this framework can set the basis for a common understanding on the obsolescence cost during contract negotiation between the customer and the prime contractor. It is acknowledged that this framework may help to consider obsolescence at the design stage, so it can be mitigated. The framework can be applied to any long-term project, predicting cost at least at the same level of accuracy as the in-house developed model existing in some companies.

This is a robust framework because much consideration has been made in the development, combining validation with experts and continuous enhancements. As a result, this framework incorporates features such as a rigorous risk assessment, the clustering factor, and the alternative obsolescence resolution profiles that can be applied when the system is reaching the end of its in-service phase. It also takes into account the uncertainty in the inputs and applies the Monte Carlo simulation to bring it into the cost estimate.

For the implementation of this framework in large companies, it is advised that the ownership should stay with a functional group of obsolescence managers, so they can customise, adapt and apply to any project where it is required. Finally, the need for an analogous framework for the cost estimation of obsolescence issues in materials has been identified. It is suggested that future research on this framework may address the limitations of the current version, including those discussed in the previous section, making the framework more robust and reliable. 


\section{ACKNOWLEDGEMENTS}

The authors would like to thank the following for assisting their research activities in this area: in particular the industrial collaborators, MoD DE\&S, BAE Systems, GE Aviation, Rolls Royce, Lockheed Martin, Thales Aerospace, Selex Galileo, COG. They also thank the EPSRC and the Cranfield University's Innovative Manufacturing Research Centre (IMRC) for funding the research. This paper is presented as part of the research undertaken by the PSS-COST project at the Decision Engineering Centre at Cranfield University. The authors would also like to thank the anonymous reviewers for their insightful and constructive comments on this paper.

\section{REFERENCES}

[1] Romero Rojo, F. J., Roy, R., Shehab, E. and Cheruvu, K. A Study on Obsolescence Resolution Profiles. (submitted to IMechE part B on $13^{\text {th }}$ December 2010)

[2] Romero Rojo, F. J., Roy, R. and Shehab, E. Hardware Obsolescence Cost Drivers for Product Support. (To be published at $24^{\text {th }}$ International Congress on Condition Monitoring and Diagnostics Engineering Management (COMADEM2011) on $30^{\text {th }}$ May 2011)

[3] Meyer, A., Pretorius, L. and Pretorius, J. H. C. A model to manage electronic component obsolescence for complex or long life systems. Engineering Management Conference, 2004 Proceedings. 2004 IEEE International, 3(1), 1303 - 1309.

[4] Singh, P. and Sandborn, P. Obsolescence Driven Design Refresh Planning for Sustainment-Dominated Systems. The Engineering Economist, 2006, 51(2), $115-139$.

[5] Madisetti, V., Jung, Y., Khan, M., Kim, J. and Finnessy, T. On upgrading legacy electronics systems: methodology, enabling technologies and tools, VHDL International Users Forum Fall Workshop, 2000. Proceedings, Orlando, FL, USA, 18-20 Oct. 2000, 7-14. 
[6] Weaver, P. and Ford, M. ATE obsolescence solutions; costs and benefits [military equipment]. AUTOTESTCON 2003. IEEE Systems Readiness Technology Conference Proceedings, 22-25 Sept. 2003, 623-628.

[7] Kerr, C. I. V., Phaal, R. and Probert, D. R. Technology insertion in the defence industry: A primer. Proc. IMechE, Part B: J. Engineering Manufacture, 2008, 222(8), 1009-1023. doi: 10.1243/09544054JEM1080

[8] Pecht, M. G. and Das, D. Electronic part life cycle. IEEE Transactions on Components and Packaging Technologies, 2000, 23(1), 190-192.

[9] Torresen, J. and Lovland, T.A. Parts Obsolescence Challenges for the Electronics Industry. Design and Diagnostics of Electronic Circuits and Systems, 2007. DDECS'07. IEEE, 11-13 April 2007, 1-4.

[10] Solomon, R., Sandborn, P. and Pecht, M. Electronic part life cycle concepts and obsolescence forecasting. Components and Packaging Technologies, IEEE Transactions on, 2000, 23(4), 707-717.

[11] Sandborn, P. Designing for Technology Obsolescence Management. Proceedings of the 2007 Industrial Engineering Research Conference, 19-23 May 2007, Nashville, TN.

[12] Adams, C. Getting a Handle on COTS Obsolescence, Avionics Magazine, 2005. http://www.aviationtoday.com/av/categories/military/887.html (accessed on 28th October 2010).

[13] Romero Rojo, F. J., Roy, R., Shehab, E. and Wardle, P. Obsolescence Challenges for Product-Service Systems in Aerospace and defence Industry. The 1st CIRP Industrial Product-Service Systems (IPS2) Conference, 1st-2nd April 2009, Cranfield University, UK.

[14] Baines, T. S., Lightfoot, H. W., Evans, S., Neely, A., Greenough, R., Peppard, J., Roy, R., Shehab, E., Braganza, A., Tiwari, A., Alcock, J. R., Angus, J. P., Bastl, M., Cousens, A., Irving, P., Johnson, M., Kingston, J., Lockett, H., Martinez, V., Michele, P., Tranfield, D., Walton, I. M. and Wilson, H. State-ofthe-art in product-service systems, Proc. IMechE Part B: J. Engineering Manufacture, 2007, 221, 1543-1552. 
[15] Behrend, S., Jasch, C., Kortmap, J., Hrauda, G., Firzner, R. and Velte, D. EcoService Development Reinventing Supply and Demand in the European Union. Greenleaf: Sheffield, 2003.

[16] Roy, R. and Cheruvu, K. A competitive framework for Industrial Product Service Systems, International Journal of Internet Manufacturing and Services. Special Issue on Product Service Solutions in Life-Cycle Activities, 2009, 2(1), 4-29.

[17] Romero Rojo, F. J., Roy, R. and Shehab, E. Obsolescence management for long-life contracts: state of the art and future trends, International Journal of Advanced Manufacturing Technology, 2009, 49(9-12), 1235-1250. doi: 10.1007/s00170-009-2471-3.

[18] Condra, L. Combating Electronic Component Obsolescence by Using Common Processes for Defense and Commercial Aerospace Electronics. IECQ-CMC Avionics Working Group1, NDIA Paper document, September 1999.

[19] Humphrey, D., Condra, L., Pendse, N., Das, D., Wilkinson, C. and Pecht, M. G. An avionics guide to uprating of electronic parts. IEEE Trans Compon Packag Technol, 2000, 23(3), 595-599.

[20] Pecht, M. and Humphrey, D. Uprating of electronic parts to address obsolescence. Microelectron Int, 2006, 23(2), 32-36.

[21] Oblad, R.P. Achieving robust interchangeability of test assets in ATE systems, AUTOTESTCON '99. IEEE Systems Readiness Technology Conference, 1999. IEEE, 1999, 687-698. doi: 10.1109/AUTEST.1999.800443.

[22] Baca, M. The third dimension in obsolescence management. Military \& Aerospace Electronics, 2005, 15-18. Available online: http://mae.pennnet.com/articles/article_display.cfm?article_id=236302 (accessed on 27th October 2010)

[23] Barton, D.L. and Chawla, P., 2003. Designing systems for future obsolescence. Digital Avionics Systems Conference, 2003. DASC'03, 2:10.C.2-101-11, 12-16 Oct. 2003, IEEE, Indianapolis, IN, USA. 
[24] Pope, S. M., Elliott, J. R. and Turbini, L. J. Designing for technological obsolescence and discontinuous change: an evaluation of three successional electronic products. Proceedings of the 1998 IEEE International Symposium on Electronics and the Environment, 1998, 280-286. doi: 10.1109/ISEE.1998.675072

[25] Perera, H. S. C., Nagarur, N. and Tabucanon, M. T. Component part standardization: A way to reduce the life-cycle costs of products, International Journal of Production Economics, 60-61, 20 April 1999, 109-116, ISSN 09255273, DOI: 10.1016/S0925-5273(98)00179-0.

[26] Hoppin, T. Strategies for mitigating risk related to the obsolescence of HP 8566/68 spectrum analyzers in ATE systems, AUTOTESTCON Proceedings, 2002. IEEE, 2002, 608- 620. doi: 10.1109/AUTEST.2002.1047943

[27] Petersen, L. The Use of Commercial Components in Defense Equipment to Mitigate Obsolescence. A Contradiction in Itself? RTO SCI Symposium on Strategies to Mitigate Obsolescence in Defense Systems Using Commercial Components, Budapest, Hungary, 23-25 October 2000, RTO MP-072.

[28] Marion, R.L., 2001. Mitigating COTS obsolescence in military test. AUTOTESTCON Proceedings, 2001. IEEE Systems Readiness Technology Conference, pp. 746-756. doi: 10.1109/AUTEST.2001.949458

[29] Craig, R. W. A methodology for addressing support equipment obsolescence. Aerospace and Electronic Systems Magazine, IEEE, 2002, 17(5), $20-25$.

[30] Redling, T. J. Considerations for upgrading aging military avionics systems with state-of-the-art technology. The 23rd Digital Avionics Systems Conference, 2004. DASC 04. 24-28 Oct. 2004, 2:7.D.1-7.1-7

[31] Josias, C., Terpenny, J. P. and McLean, K. J. Component obsolescence risk assessment. Proceedings of the 2004 Industrial Engineering Research Conference (IERC), 15-19 May 2004.

[32] Sandborn, P., Mauro, F. and Knox, R. A data mining based approach to electronic part obsolescence forecasting. IEEE Transactions on Components and Packaging Technologies, 2007, 30(3), 397-401. 
[33] Sandborn, P., Prabhakar, V. and Ahmad, O. Forecasting electronic part procurement lifetimes to enable the management of DMSMS obsolescence, Microelectronics Reliability, In Press, Available online 3 September 2010, ISSN 0026-2714, DOI: 10.1016/j.microrel.2010.08.005.

[34] Singh, P., Sandborn, P., Geiser, T. and Lorenson, D. Electronic part obsolescence driven design refresh planning. International Journal of Agile Manufacturing, 2004, 7(1), 23-32.

[35] Singh, P., Sandborn, P., Lorenson, D. and Geiser, T. Determining Optimum Redesign Plans for Avionics Based on Electronic Part Obsolescence Forecasts. Proc. World Aviation Congress, November 2002, Phoenix, AZ, SAE International.

[36] Feldman, K. and Sandborn, P. Integrating Technology Obsolescence Considerations into Product Design Planning. Proceedings of the ASME 2007 International Design Engineering Conferences \& Computers and Information in Engineering Conference, Sept. 2007, Las Vegas, NV.

[37] Feng, D., Sandborn, P. and Singh, P. Optimizing Lifetime Buy Quantities to Minimize Lifecycle Cost. MSc Thesis, University of Maryland, 2007. Available online http://www.lib.umd.edu/drum/bitstream/1903/6740/1/umi-umd-4217.pdf (accessed on 8th April 2009).

[38] MoD, 2004. Ministry of defence component obsolescence resolution cost metrics study, QinetiQ and ARINC, UK. Available online http://www.aof.mod.uk/aofcontent/tactical/engineering/downloads/om_resolution _metrics_2004.pdf (accessed 18th October 2010)

[39] Rush, C. and Roy, R. Expert judgement in cost estimating: Modelling the reasoning process, Concurrent Engineering, 2001, 9(4), 271-284.

[40] Cheung, W. M., Marsh, R., Newnes, L. B., Mileham, A. R. and Lanham, J. D. Standards and inference of design information in through life costing of innovative defence electronic products, Proceedings of the Institution of Mechanical Engineers, Part B: Journal of Engineering Manufacture, 2009, 223(2), 169-181. ISSN 0954-4054, DOI: 10.1243/09544054JEM1315. 
[41] Westkamper, E., Niemann, J. and Dauensteiner, A. Economic and Ecological Aspects in Product Life Cycle Evaluation. Proceedings of the Institution of Mechanical Engineers, Part B: Journal of Engineering Manufacture, 2001, 215(5), 673-681. ISSN 0954-4054, DOI: 10.1243/0954405011518601. 